Volume 9, No.4, July - August 2020

International Journal of Advanced Trends in Computer Science and Engineering

Available Online at http://www.warse.org/IJATCSE/static/pdf/file/ijatcse167942020.pdf

https://doi.org/10.30534/ijatcse/2020/167942020

\title{
Bio Impedance Signal Analysis with Variation in Input Signal Frequency
}

\author{
Sheeba Santhosh ${ }^{1}$, A. Vimala Juliet ${ }^{2}$, G. Hari Krishnan ${ }^{3 *}$ \\ ${ }^{1}$ Research Scholar, Sathyabama Institute of Science \& Technology, India \\ ${ }^{2}$ Professor, Department of ICE, SRM Institute of Science \& Technology, India \\ ${ }^{3 *}$ Associate Professor, Department of EEE, SreeVidyanikethan Engineering College,Tirupati, India \\ Corresponding Author E-mail:haris_eee@yahoo.com
}

\begin{abstract}
The critical need for the monitoring of cardiac diseases on a regular basis has led to the development of non-invasive techniques. The non-invasive techniques have tremendous advantage as compared to invasive techniques in terms of its measurement difficulties and the complications of circuit design. One such noninvasive technique used in our study is bio-impedance method of diagnosing of diseases. In this paper we analyzed bio-impedance signal changes with respect to the changes in the input excitation signal frequency variations. AD5933EBZ evaluation board were used as hardware tool to carry out the bio-impedance signal analysis.
\end{abstract}

Key words : Signal Frequency, Input excitation, bio-impedance signal, Magnitude and Impedance Analyzer.

\section{INTRODUCTION}

Bioimpedance methods completely depend on the application of low intense high frequency current on the surface of a tissue. AD5933 variable frequency signal generator with impedance measuring system based development board was used [1][2]. The conventional method of invasive techniques where replaced by noninvasive methods. The use of electrocardiogram and photo plethysmography was prevalent for examining the state of the patient [3][4]. But it was observed that, these methods encounters signal variations at different instances of time depending on the physical movement of the subject and also the environment in which the measurement is carried out affects the values obtained [5][6]. A novel approach to overcome such difficulties is the bioimpedance method which has been developed long back, but its effectiveness in measuring heart diseases has increased in recent studies [7].

Bioimpedance techniques reveal the fact that human body acts as a conductor and it has a resistance associated with it which is known as bioimpedance because of the presence of ions in the cellular structure [8][9]. Bioimpedance of a tissue or a cell or human body is measured by applying a low intensity high frequency current which causes variation in the impedance of a tissue or cell, resulting in a change in voltage that can be measured[10]. Bioimpedance is a complex quantity which has resistance as areal part and reactance as imaginary part and is expressed as $\Omega$ [11][12].

$$
\mathrm{Z}=\mathrm{R}+\mathrm{j} \mathrm{X}_{\mathrm{c}}
$$

Where resistance represents the resistance of the cell to the flow of current and the reactance represents the opposition to the flow of current [13][14]. The bioimpedance is depended on the frequency and it varies according to the applied frequency [15]..[17]. The bioimpedance value of tissues will help us to identify any physiological and pathological changes [18][19]. The applications of bioimpedance include determination of composition of body, in nephrology which aids in dialysis, impedance cardiography to detect heart diseases, electrical impedance tomography which provides the images of internal parts of the body [20][21].

The main aspect of bioimpedance measurement system is the electrode [22].. [24]. These electrodes act as an interface between the human body and the recording instrument through electrical and chemical changes [25][26].

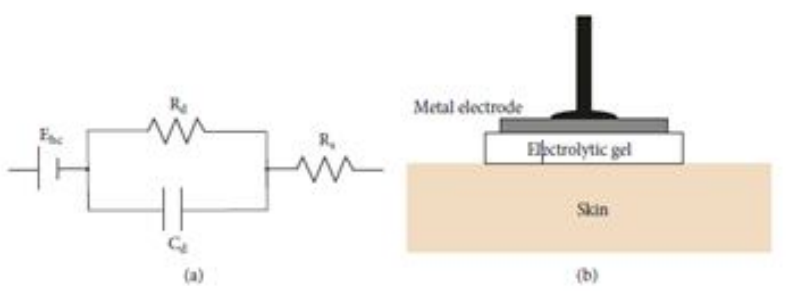

Figure 1: a) General Electrode Model b) Electrode Element

As shown in the figure 1, a generalized electrode model consists of the external layer of the skin, a metallic electrode and an electrode gel [27] .. [29]. The functionality of the gel is to increase the conductivity to the electric current [30] .. [32]. There are different types of electrodes used for biosignal recording. Gold electrode in the form of paste is generally available as two concentric helical structures which are used to measure the moistness of the sweat in the skin [33][34]. In order to overcome the demerits of direct contact of electrodes with the skin, capacitive type electrodes[35][36] were used 
but the results were not satisfactory [37]. Active type of electrodes replaced capacitive type of electrodes by using amplifiers with input impedance which is high and output impedance which is low [38]. In medical applications now a days garment electrodes are used to measure and monitor the vital parameters of a patient [39].

In Impedance cardiography, most common type of electrodes used is silver-silver chloride electrode which has shown a great advantage in the impedance measurement system [40][41]. There are different ways of using the electrodes for measurement. Electrodes can be used as two electrode system, four electrode systems, eight electrode systems are used for measurement.

\section{EXPERIMENTAL METHODS AND RESULTS}

The most important aspect of bioimpedance measurement for a cardiac system depends on the placement of electrodes for the accurate measurement of bio signal. In this paper we have reviewed the placement of electrodes and its performance for impedance measurement.

A pair of electrodes acts as current injecting electrodes to inject a high frequency low intense current. It is generally placed in the upper part of the laterocervical region that is the root of the neck. The other two electrodes are placed in the midaxillary line at the upper abdomen region as shown in figure 2 . The electrical current thus injected is mainly passed through the thoracic aorta and the venae cavae [21]. The electric current is mainly associated with the blood flow which flows throughthe thoracic aorta and venae cavae and it produces thoracic impedance corresponding to the blood flow variations. Generally, a high frequency $(500 \mathrm{~Hz}$ to $10 \mathrm{kHz})$ constant current (less than $10 \mathrm{~mA}$ ) source is used for impedance measurement. The impedance signal generated is dependent on the flow and volume of blood, current distribution and the change in resistance of the blood flow in that particular region where the electrodes are placed.

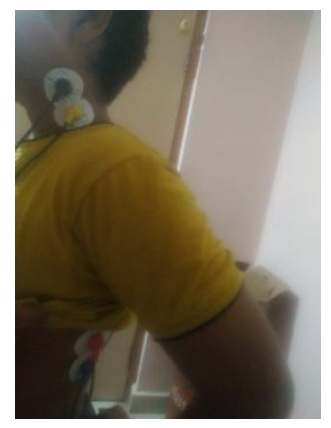

Figure 2: Electrode placement in the neck and chest

A high gain high input impedance instrumentation amplifier picks up the changes in the voltage from the forearm. To remove the superimposed power line noise a band reject filter is used. Filtered signal is rectified and pass through the band pass filter to demodulate the required signal and is amplified with a high gain amplifier.
Experiment were conducted using AD5933EBZ evaluation board by Analaog Electronics. Initial configuration were done with start frequency set at $500 \mathrm{~Hz}$, Delta Frequency $50 \mathrm{~Hz}$ with number of increments was set at 100. During frequency sweep each frequency value will stay for 14 seconds. Input excitation signal was set to sine wave of $2 \mathrm{~V}$ peak to peak. Proper calibration was carried out by setting the value of feedback resistance between Vin and Vout voltage nodes for getting un distorted impedance wave.

Table 1: Impedance and Magnitude values with respect to input signal frequency variation.

\begin{tabular}{|c|c|c|c|}
\hline S.No & Frequency & Impedance & Magnitude \\
\hline 1 & 500 & 1548824.901 & 26831.57875 \\
\hline 2 & 650 & 1625027.423 & 25573.36368 \\
\hline 3 & 1200 & 2604324.38 & 15957.08184 \\
\hline 4 & 1250 & 2809736.738 & 14790.50216 \\
\hline 5 & 1350 & 3347217.795 & 12415.51038 \\
\hline 6 & 1800 & 5923798.668 & 7015.332494 \\
\hline 7 & 1950 & 5046874.131 & 8234.288433 \\
\hline 8 & 2000 & 4805940.324 & 8647.093905 \\
\hline 9 & 2050 & 4604047.377 & 9026.279245 \\
\hline 10 & 2150 & 4318437.412 & 9623.253348 \\
\hline 11 & 3100 & 3429180.683 & 12118.75988 \\
\hline 12 & 3850 & 2946704.215 & 14103.0162 \\
\hline 13 & 3900 & 2913584.868 & 14263.32822 \\
\hline 14 & 3950 & 2882008.267 & 14419.60377 \\
\hline 15 & 4000 & 2851239.092 & 14575.21307 \\
\hline 16 & 4950 & 2472857.69 & 16805.4221 \\
\hline 17 & 5000 & 2458582.335 & 16903.00003 \\
\hline 18 & 5050 & 2446136.074 & 16989.00471 \\
\hline 19 & 5450 & 2371862.581 & 17521.00548 \\
\hline 20 & 5500 & 2366312.087 & 17562.10329 \\
\hline & & & \\
\hline
\end{tabular}

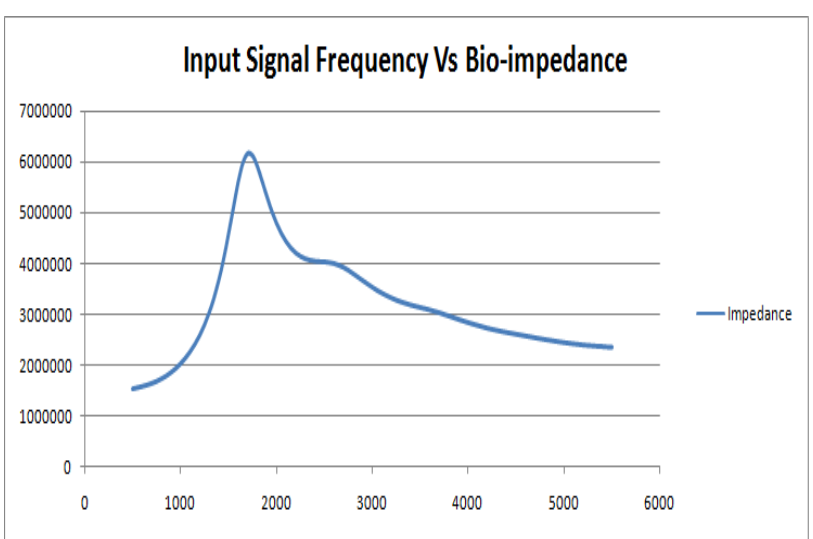

Figure 3: Bio-impedance variation with respect to change in input signal frequency. 
Once the initial configuration was done program device register was loaded with the set values and made the setup to calculate the value of gain factor. Frequency sweep option was selected to excited the part upder study with differenct set frequencies. Experimental values of input signal excitation frequency, Impedance value and magnitude are tabluated as shown in table 1. Graphs where plotted between excitation signal frequency in $\mathrm{x}$-axis and its corresponding variation in bio-impedance and magnitude were plotted in y-axis as shown in figure 3 and figure 4.

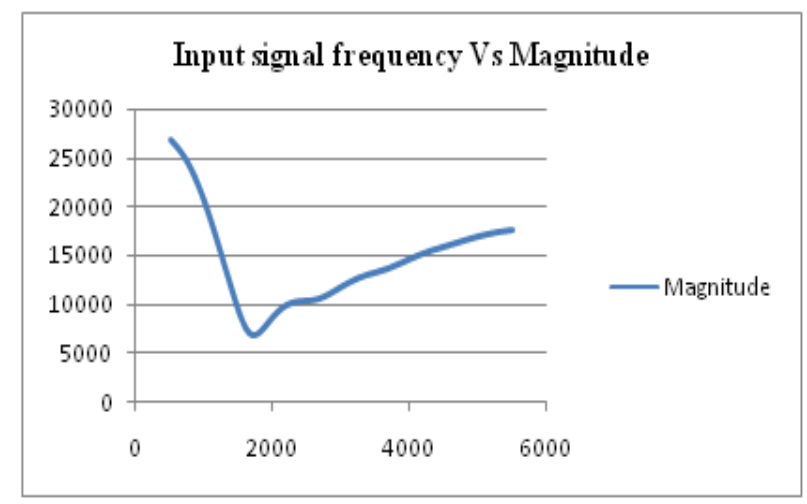

Figure 4: Magnitude and Phase variation with respect to change in input signal frequency

\section{CONCLUSION}

Analysis of bio-impedance signal with respect to frequency variation on the input excitation signal was performed. Magnitude and impedance variation due to the change in applied signal frequency on input electrodes under bio-impedance diagnosis were analyzed. It has been observed that resonance frequency where peak magnitude was obtained varies between $1700 \mathrm{~Hz}$ to $1800 \mathrm{~Hz}$ for various electrode distances.

\section{ACKNOWLEDGEMENT}

The authors of this research work were thankful to Department of Biomedical Engineering, Sathyabama University and Centre for Energy, Sree Vidyanikethan Engineering College for providing needed support in all means.

\section{CONFLICT OF INTEREST}

The three authors of this paper have no conflict of interest in any means.

\section{REFERENCES}

1. Krishnan, G.H, Nanda, A., Natarajan, A. Synovial fluid density measurement for diagnosis of arthritis, Biomedical and Pharmacology Journal 7(1), 221-224, 2014. https://doi.org/10.13005/bpj/476

2. M. A. Callej'on, P. del Campo, J. Reina-Tosina, and L. M. Roa. A parametric computational analysis into galvanic couplingintrabody communication, IEEE
Journal of Biomedical andHealth Informatics, vol. 22, no. 4, pp. 1087-1096, 2018.

3. B. Taji, S. Shirmohammadi, V. Groza, and I. Batkin. Impact of skin-electrode interface on electro cardiogram measurements using conductive textile electrodes, IEEE Transactions on Instrumentation and Measurement, vol. 63, no. 6, pp. 1412-1422, 2014.

https://doi.org/10.1109/TIM.2013.2289072

4. M. H. Jones and J. Scott. Scaling of electrode-electrolyteinterface model parameters in phosphate buffered saline, IEEE Transactions on Biomedical Circuits and Systems, vol. 9, no. 3, pp. 441-448, 2015.

5. K. Dudzinski, M. Dawgul, K. D. Pluta, B. Wawro, W. Torbicz, and D. G. Pijanowska. Spiral concentric two electrode sensorfabricated by direct writing for skin impedance measurements, IEEE Sensors Journal, vol. 17, no. 16, pp. 5306-5314, 2017.

6. B. Eilebrecht, J. Willkomm, A. Pohl, T. Wartzek, and S. Leonhardt. Impedance measurement system for determination of capacitive electrode coupling, IEEE Transactions on Biomedical Circuits and Systems, vol. 7, no. 5, pp. 682-689, 2013.

7. Predrag Stevanović, Radislav Šćepanović, Dragan Radovanović, Đorđe Bajec, Radoslav Perunović, Dragoš Stojanović, Dejan Stevanović. Thoracic electrical bioimpedance theory and clinical possibilities in perioperative medicine, Signa Vitae 2008; 3 SUPPL 1: S $22-27$.

8. Gong WeiYan, LV JingHua, Wang Yan, Sha Hong, Zhao Shu, Ren ChaoShi. The impedance property of Electrode used in Electrical Bio-impedance Measurement, 3rd International Conference on Bioinformatics and Biomedical Engineering, Beijing, China, IEEE Xplore2009;11-13.

https://doi.org/10.1109/ICBBE.2009.5163623

9. Guru Anand, V., Hari Krishna, G., Mohandass, G., Hemalatha, R.J., Sundaram, S. Predicting grade of prostate cancer using image analysis software, Proceedings of the 2nd International Conference on Trendz in Informtion Sciences and Computing, TISC-2010, 5714621, pp. 122-124, 2010.

10. Krishnan, G.H., Natarajan, R.A., Nanda, A. Microcontroller based non invasive diagnosis of knee joint diseases, International Conference on Information Communication and Embedded Systems, ICICES 2014, 7034178, 2015.

11. Jia-Jung Wang, Wei-Chih Hu, Tsiar Kao, Chun-Peng Liu and Shih-Kai Lin, Development of forearm impedance plethysmography for minimally invasive monitoring of cardiac pumping function, Journal of Biomedical Science and Engineering 2011; Vol.4, pp:122-129.

12. TusharKantiBera, Bioelectrical Impedance Method for Noninvasive Health Monitoring:, A Review, Journal of Medical Engineering 2014; pp:1-28,

13. Hari Krishnan, G.H., Ananda Natarajan, R., Nanda, A. Impact of upper limb joint fluid variation on inflammatory diseases diagnosis, Journal of Electrical Engineering and Technology, 9(6), 2114-2117, 2014. 
14. Wang Lei. The effect of medical electrodes on ECG \& EEG verification instrument measurement, Practical medical technology journal 2007; vol.4(20), pp: 2625-2626.

15. RenChaoShi, Wang Yan, Deng Juan, The application study of Electrical Impedance Tomography, Chinese Journal of Medical Instrumentation 2007; vol. 31 (4), pp:235-238.

16. Krishnan, G.H, Natarajan, R.A., Nanda, A. Comparative study of rheumatoid arthritis diagnosis using two different methods, Biomedical and Pharmacology Journal, 7(1), 379-382, 2014.

17. Suxian Cai, Shanshan Yang, Fang Zheng, Meng Lu, YunfengWu, \& Sridhar Krishnan, Knee Joint Vibration Signal Analysis with Matching Pursuit Decomposition and Dynamic Weighted Classifier Fusion, Computational and Mathematical Methods in Medicine 2013; pp.1-11.

18. Tanaka, N.I, Miyatani, M, Masuo, Y, Fukunaga, T, Kanehisa, H, Applicability of a segmental bioelectrical impedance analysis for predicting the whole body skeletal muscle volume, J. Appl. Physiol., 2007; vol.103, pp.1688-1695.

19. Kun-Yang,Wen-HuiCHEN, Lian-Rong ZHEN, Shan-Qing WANG, Xian-Ming, Guan-Zheng LIU, A method to detect heart rate based on electrical bio-impedance, ITM Web of Conferences 477, 09014 (2016) https://doi.org/10.1051/itmconf/20160709014

20. Hari Krishnan, G., Abhinaya, N., Hemalatha, R.J., Mohandass, G., Hardware implementation for feedback control based health monitoring and drug delivery, Biomedicine (India), 37(1), pp.123-126, 2017.

21. Nandhini, P., Hari Krishnan, G., Umashankar, G. Home based telemedicine system for respiratory disorder, International Journal of Pharma and Bio Sciences, 6(4), pp.8227-8231, 2015.

22. Sudhakar, T., Hari Krishnan, G., Santosh, S., Meenakshi, S., Thomas, Prosthetic arm control using processing device, a comparative approach, Biomedical Research (India), 29(13), pp.2904-2907, 2018.

23. Mohandass, G., Ananda Natarajan, R., Hari Krishnan, G. Comparative analysis of optical coherence tomography retinal image using multidimensional and cluster methods. Biomedical Research (India), 26(2), pp.273-285, 2015.

24. Nagarjuna Reddy, A., Hari Krishnan, G., Raghuram, D., Real time patient health monitoring using raspberry PI, Research Journal of Pharmaceutical, Biological and Chemical Sciences, 7(6), pp.570-575, 2016.

25. Hari Krishnan, G., Umashankar, G., Abraham, S., Cardiovascular disorder diagnosis using MR angiography, Biomedical Research (India), 27(3), pp.773-775, 2016.

26. Margreat, L., Hari Krishnan, G. Stastical approach for diagnosis of diseases using histopathology data, International Journal of Pharma and Bio Sciences, 6(2), pp. B199-B203, 2015.

27. Umashankar, G., Hari Krishnan, G., Abraham, S., (...), Kirubika, T.R., Rajendran, M. Proximity sensing system for retinal surgery patients, Journal of Chemical and Pharmaceutical Sciences, 8(4), pp. 607-610, 2015.

28. Ilangovan, N., Hari Krishnan, G. Wheel chair movement control using human input: Comparative study approach, Research Journal of Pharmaceutical, Biological and Chemical Sciences, 6(3), pp.568-570, 2015.

29. Radhakrishna Rao, G., Hari Krishnan, G. Comparative study of pacemaker energy harvesting techniques, Research Journal of Pharmaceutical, Biological and Chemical Sciences, 6(1), pp.1545-1547, 2015.

30. Sabarivani, A., Hari Krishnan, G. Home health assistive system for critical care patients, Research Journal of Pharmaceutical, Biological and Chemical Sciences, 6(2), pp.629-633, 2015.

31. Hari Krishnan, G., Hemalatha, R.J., Umashankar, G., Ahmed, N., Nayak, S.R., Development of Magnetic Control System for Electric Wheel Chair Using Tongue, Advances in Intelligent Systems and Computing 308 AISC, Vol.1, pp.635-641, 2015.

32. Hemalatha, R.J., Krishnan, G.H., Umashankar, G., Abraham, S. Computerized breast cancer detection system, Biosciences Biotechnology Research Asia, Vol. 11(2), pp.907-910, 2014. https://doi.org/10.13005/bbra/1357

33. Abraham, S., Krishnan, G.H., Hemalatha, R.J., Divakaran, S., Umashankar, G. Design of voice based pill ejector system, Biomedical and Pharmacology Journal, 7(1), pp.231-234, 2014.

34. Umashankar, G., Hari Krishnan, G., Hemalatha, R.J., Abraham, S., Divakaran, S. Assistive system for remote accident patients, Research Journal of Pharmaceutical, Biological and Chemical Sciences, 5(5), pp.516-520, 2014.

35. Santhosh, S., Vimala Juliet, A., Hari Krishnan, G. Simulation of Signal Generator and Measuring Circuit and Real Time IoT Based Electrical Bio Impedance Cardiac Monitoring System, Advances in Intelligent System and Computing, 1039, pp. 701-706, 2020. https://doi.org/10.1007/978-3-030-30465-2_77

36. Mohandass, G., Hari Krishnan, G., Hemalatha, R.J. An approach to automated retinal layer segmentation in SDOCT images, International Journal of Engineering and Technology(UAE), 7(2), pp. 56-63, 2018.

37. Hari Krishnan, G., Arun Kumar, G.S., Arun, V, Saravanan, R. Comparative study of diabetes foot diagnosis using ABPI, International Journal of Engineering and Technology(UAE), 7(2), pp. 40-42, 2018.

38. Sheeba Abraham, G. Umashankar, G. Harikrishnan, Anam Akter, Subhalakshmi.C Optical Probe system for differentiating tissues using the optical characterstics of DRS, Journal of Chemical and Pharmaceutical Sciences", 8(1), pp. 137-141, 2015.

39. Mahima Shanker Pandey, Sudhir Singh Soam, Surya Prakash Tripathi. Computerized gender determination from human sternum and manubrium x-ray measurements, International Journal of Advanced 
Trends in Computer Science and Engineering,Vol. 8(6), pp.2730-2734, 2019.

https://doi.org/10.30534/ijatcse/2019/01862019

40. D. Sherlin, Dr. D. Murugan. Brain Tumor segmentation using modifeid Fuzzy metric based Approach with adaptive technique, International Journal of Advanced Trends in Computer Science and Engineering,Vol. 8(6), pp.2686-2692, 2019.

https://doi.org/10.30534/ijatcse/2019/08862019

41. Santhosh, S., Juliet, A.V. \& Krishnan, G.H. Predictive analysis of identification and disease condition monitoring using bioimpedance data. J Ambient Intell Human Comput (2020).

https://doi.org/10.1007/s12652-020-02452-7. 